\title{
Antioxidant Protective Effects of the Resveratrol on the Cardiac and Vascular Tissues from Renal Hypertensive Rats
}

\author{
Joyce Cristina de Oliveira ${ }^{1}$, Carla Renata Kitanish Antonietto ${ }^{2}$, Angélica Cristina Scalabrini ${ }^{2}$,

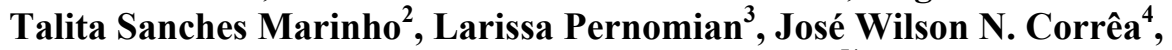 \\ Carolina Baraldi Araujo Restini ${ }^{*}$ \\ ${ }^{1}$ School of Nutrition, University of Ribeirão Preto, Ribeirão Preto, Brazil \\ ${ }^{2}$ School of Pharmaceutical Sciences, University of Ribeirão Preto, Ribeirão Preto, Brazil \\ ${ }^{3}$ Department of Physics and Chemistry, Faculty of Pharmaceutical Sciences from Ribeirão Preto, \\ Laboratory of Pharmacology, University of São Paulo, Ribeirão Preto, Brazil \\ ${ }^{4}$ Federal University of Amazonas, Manaus, Brazil \\ ${ }^{5}$ School of Medicine, Animal Experimental Laboratory, University of Ribeirão Preto, \\ Ribeirão Preto, Brazil \\ Email: *carolbaraldi@hotmail.com.br
}

Received May 13, 2012; revised June 20, 2012; accepted July 1, 2012

\begin{abstract}
Background: Accumulating reactive oxygen species (ROS) is involved in cellular signaling and function disturbances due to the oxidative stress, which contributes to several diseases. The consequences of ROS activity represent an important mechanism on the pathogenesis of vascular diseases, such as hypertension. Increased blood pressure observed in renal hypertension of the 2 kidneys-1 clip (2K-1C) model involves increased ROS levels in the cardiovascular system. Resveratrol, a polyphenolic compound primarily found in red wine, has many biological and pharmacological properties. Considering the antioxidant properties of resveratrol, the present study was aimed to investigate the effects of the chronic treatment with resveratrol on cardiovascular system from renal hypertensive rats. Results: $2 \mathrm{~K}-1 \mathrm{C}$ hypertension presented increased blood pressure, which was reduced at the end of the fifth week of resveratrol treatment. The cardiac hypertrophy index and the basal levels of ROS in rat aortic rings were also reduced by resveratrol treatment. Conclusions: The present findings clearly show the protective effects from resveratrol on the blood pressure, the cardiac growth and the vascular ROS generation in renal hypertension.
\end{abstract}

Keywords: Hypertension; Aorta; Superoxide; Resveratrol; Phenylephrine; Reactive Species of Oxygen (ROS)

\section{Introduction}

Hypertension is a well-studied risk factor for several car diovascular diseases. It has been established that hypetension is associated with cardiovascular damages such as endothelial dysfunction, microvascular impairments [1] and cardiovascular remodeling [2,3]. The pathological processes underlying hypertension have been extensively studied by applying some animal models [4], such as the 2-kidneys-1Clip (2K-1C) renovascular hypertension. In this model, designed by Goldblatt and cols in 1934 [5], a partial stenosis in the left renal artery is caused by placing a silver clip on the arterial side close to the aorta. This stenosis elicits a sustained increase in blood pressure mainly due to the increased plasma renin activity and subsequent increased circulating angiotensin-II (Ang

${ }^{*}$ Corresponding author.
II) [6]. Furthermore, an overproduction of superoxide anion $\left(\mathrm{O}_{2}^{-}\right)$has been observed in some vessels from $2 \mathrm{~K}-1 \mathrm{C}$ hypertensive an imals [7-9]. In $2 \mathrm{~K}-1 \mathrm{C}$ pigs, the increased plasma renin activity and high blood pressure (BP) have been correlated to increased systemic oxidative stress [10-13]. Indeed, hypertensive patients with renovascular disease have shown a markedly in creased lipid peroxidation, which is partly related to the activation of the Renin-Angiotensin System (RAS) [8]. One of the most relevant damages caused by oxidative stress underlying hypertension and correlated diseases is the impairment of endothelium-dependent vasorelaxation mechanisms $[9,10]$, which is generally related to the reduced endothelial nitric oxide (NO) generation or bioavailability [14-16]. In turn, the reduced NO bioavailability has been attributed to the oxidative inactivation of $\mathrm{NO}$ by the excessive generation of $\mathrm{O}_{2}^{-}$in the vascular wall 
[17]. Besides the vessels, ROS generation also affects the heart. It is well-known that hydrogen peroxide $\left(\mathrm{H}_{2} \mathrm{O}_{2}\right)$ impairs cardiac contraction and evokes cardiac hypertrophy [18]. Indeed, substantial evidence has pointed to oxidative stress as a major pathway in the cardiac remodeling and the transition of compensated cardiac hypertrophy during heart failure [19-23]. The consumption of flavonoid-rich food is associated to the reduced risk of many acute diseases. This protective effect is, at least in part, due to the antioxidant properties from flavonoids [24]. Part of the cardiovascular protective effects of red wine has been attributed to resveratrol, a polyphenolic compound present in the red grape skin [25]. The study of the biological properties from resveratrol began in the $80 \mathrm{~s}$, but it became more extensive in the $90 \mathrm{~s}$ due to the French Paradox [26,27]. According to Renaud and Lorgeril [26], in most countries, high intake of saturated fat is positively related to high mortality from coronary heart disease (CHD). However, the situation in France is paradoxical in that there is high intake of saturated fat but low mortality from coronary heart disease. This paradox may be attributable in part to high wine consumption. Resveratrol acts as an active antioxidant by donating hydrogen protons to free radicals and by inhibiting lipid peroxidation and oxidizing enzymes [28]. Also, resveratrol stimulates the acute release of NO from endothelial cells, which improves NO-mediated vasorelaxation mechanisms [29]. Since oxidative stress impairs the cardiovascular function in $2 \mathrm{~K}-1 \mathrm{C}$ renovascular hypertension, the hypothesis from the present study is that the chronic treatment of $2 \mathrm{~K}-1 \mathrm{C}$ hypertensive rats with resveratrol would reduce the cardiovascular damages through the antioxidant properties of the polyphenol. Thereby, our aim was to evaluate the antioxidant effects of the chronic treatment with resveratrol on the structural and functional damages in $2 \mathrm{~K}-1 \mathrm{C}$ rat aorta and heart.

\section{Materials and Methods}

\subsection{Experimental Groups and Resveratrol Treatment}

All procedures were performed in agreement with international ethical standards of animal experimentation and approved by the Ethics Committee of the University of Ribeirão Preto (protocol No. 007/2010). Animals were maintained on a standard rat chow with a 12-hlight/dark cycle and free access to food and water. Renovascular hypertension was induced in male Wistar rats $(180 \mathrm{~g}$ $220 \mathrm{~g}$ ) following the $2 \mathrm{~K}-1 \mathrm{C}$ Goldblatt model [5]. Briefly, the rats were anaesthetized $(0.2 \mathrm{~mL}$ of Ketamine chloride and $0.1 \mathrm{~mL}$ of Xylazine hydrochloride, ip), and a midline laparotomy was performed. Then, a silver clip $(0.2 \mathrm{~mm}$ of internal diameter) was placed around the left renal artery. Sham-operated rats were only submitted to lapa- rotomy, without the silver clip placing. Thus, these animals were named as the 2 kidneys (2K) group. One day after the surgery, the chronic treatment with resveratrol started, by gavage $(20 \mathrm{mg} / \mathrm{Kg}$, prepared in $0.05 \%$ Tween 80 suspension), which was performed three times a week, during six weeks. Juan et al. [30] had proved the safety and effectiveness of the oral treatment with resveratrol $(20 \mathrm{mg} / \mathrm{Kg})$ in rats. In this sense, we have defined this dose for the treatment.

$2 \mathrm{~K}$ or $2 \mathrm{~K}-1 \mathrm{C}$ rats received the solution containing resveratrol + Tween 80 or water + Tween 80 by gavage. Thus, our study was composed by four experimental groups, as follows: 1) $2 \mathrm{~K}$ rats treated with water + Tween 80 solution ( $2 \mathrm{~K}$ control group); 2 ) $2 \mathrm{~K}$ rats treated with resveratrol + Tween 80 suspension (2K Resv group); 3 ) $2 \mathrm{~K}-1 \mathrm{C}$ rats treated with water + Tween 80 solution ( $2 \mathrm{~K}-1 \mathrm{C}$ control group); and 4) $2 \mathrm{~K}-1 \mathrm{C}$ rats treated with resveratrol + Tween 80 suspension (2K-1C Resv group).

\subsection{Blood Pressure Measurements}

Systolic blood pressure (SBP) was measured one day before the surgery (control). After the surgery SBP was weekly measured in non-anaesthetized animals by an indirect tail-cuff method [31]. Rats were considered hypertensive when SBP was higher than $160 \mathrm{~mm} \mathrm{Hg}$ [31].

\subsection{Rat Euthanasia}

The experimental procedures described below were performed at the end of the sixth week of the treatment. The animals were euthanized by $\mathrm{CO}_{2}$ exposure followed by cervical dislocation (Office of Laboratory Animal Welfare, National Institutes of Health, US Department of Health and Human Services, 2002. Public Health Service Policy on Humane Care and Use of Laboratory AnimalsClarification Regarding Use of Carbon Dioxide for Euthanasia of Small Laboratory Animals.

(http://grants.nih.gov/grants/olaw/olaw.htm).

\subsection{Cardiac Hypertrophy Index}

Rat thoracic cavity was opened to expose the heart, which was quickly removed and washed in cold saline $0.9 \%$. Excess of the saline was gently removed with filter paper and the heart was weighed. The cardiac hypertrophy index (CHI) was calculated from the heart weight and the animal body weight, which was obtained in the day of the experiment, as follows: $\mathrm{CHI}=$ heart wet weight $(\mathrm{mg}) /$ body weight $(\mathrm{g}) \times 1000$ [32].

\subsection{Vascular Reactivity Studies}

Rat thoracic aorta was isolated for the vascular reactivity studies. Aortic rings (3 $\mathrm{mm}$ in length) were placed in isolated organ bath chambers $(5 \mathrm{ml})$ containing Krebs Physiological Salt solution (in mmol/L: $\mathrm{NaCl} 130.0 ; \mathrm{KCl}$ 
4.7; $\mathrm{KH}_{2} \mathrm{PO}_{4}$ 1.2; $\mathrm{CaCl}_{2}$ 1.6; $\mathrm{MgSO}_{4}$ 1.2; $\mathrm{NaHCO}_{3}$ 14.9; glicose 5.5 ) at $37^{\circ} \mathrm{C}$, continuously bubbled with $95 \% \mathrm{O}_{2}$ and $5 \% \mathrm{CO}_{2}$, at $\mathrm{pH}$ 7.4. Two stainless steel holders were placed through the lumen of the aortic rings. One of the holders was fixed to the tissue chamber and the other one was connected to a F-60 force-displacement transducer, in order to record the muscular tension on a polygraph (Power Lab 2/20, 415-ADInstruments). The aortic rings were submitted to a basal tension of $1.5 \mathrm{~g}$, for a $60 \mathrm{~min}$ equilibration period before drug addition. The optimal basal tension $(1.5 \mathrm{~g})$ in aortic rings from $2 \mathrm{~K}$ or $2 \mathrm{~K}-1 \mathrm{C}$ rats, treated or not with resveratrol, was previously standardized by exposing the vessels to $90 \mathrm{mmol} / \mathrm{L} \mathrm{KCl}$ under a set resting tensions $(0.5 \mathrm{~g}-2.5 \mathrm{~g})$. The arterial functional viability was tested by phenylerpine (PHE, $0.1 \mu \mathrm{mol} / \mathrm{L}$ ). The main vascular ROS source is the endothelium [33, 34]. Since the aim of this set of experiments was to investigate the direct effects of the treatment with resveratrol on the vascular tone, the endothelial layer from aortic rings was removed. Thus, in all vascular reactivity protocols, the endothelium was mechanically removed by gently rubbing. The absence of the endothelium was confirmed with no $(0 \%)$ relaxation to acetylcholine $(1 \mu \mathrm{mol} /$ L) after the pre-contraction with PHE $(0.1 \mu \mathrm{mol} / \mathrm{L})$.

\subsection{Vascular ROS Measurement by Confocal Microscopy}

Aortic rings $(250 \mu \mathrm{m}$ thick) were placed in a coverslip covered with poly-L-lysine solution, and loaded with the fluorescent dye for ROS, dihydroethidium (DHE, 50 $\mu \mathrm{mol} / \mathrm{L}, 30 \mathrm{~min}$, at $37^{\circ} \mathrm{C}$ ), which was prepared in Hanks solution (composition in mmol/L: $\mathrm{CaCl}_{2} 1.6 ; \mathrm{MgSO}_{4} 1.0$; $\mathrm{NaCl} 145.0 ; \mathrm{KCl}$ 5.0; $\mathrm{NaH}_{2} \mathrm{PO}_{4}$ 0.5; dextrose 10.0; HEPES 10.0), at $\mathrm{pH}$ 7.4. The excess of the dye was removed by washing with Hanks solution. After washing, the coverslips were placed on a chamber with Hanks buffer (pH 7.4). The ROS level was assessed by a confocal laser microscope (Leica TSC SP5). DHE was excited with the $488 \mathrm{~nm}$ line of an argon ion laser at 570 $\mathrm{nm}$ and the emitted fluorescence was measured at 650 $\mathrm{nm}$. Time course software was used to capture images of the tissues at 1.314 second intervals (xyt) in the Live Data Mode acquisition. By applying the laser scanning confocal microscope (LSCM) computer software, the intracellular minimum or maximum fluorescence intensity values were measured. From these data, the initial fluorescence value at $t=0 \mathrm{~s}$ was taken as the basal fluorescence $\left(\mathrm{F}_{0}\right)$, and the final fluorescence intensity value (F) was registered after PHE addition $(0.1 \mu \mathrm{mol} / \mathrm{L})$, at $t=100 \mathrm{~s}$.

The confocal fluorescence experiments were conducted in the "Live Data Mode". Thus, the images were captured in function of the time, which required that the calibration was set up in a xyt way (but not in a xyz way). After the regions of interest (ROI: cells) were chosen, the fluorescence intensity values were captured. The fluorescence was considered from each selected ROI, in each layer (endothelium or smooth muscle) of each aortic ring. In our study, we selected a fixed number of five (05) ROI in each arterial layer from each rat aorta. This approach allowed us to compare the fluorescence intensity values between these two arterial layers. Afterwards, the average of the fluorescence in each selected cell in its respecttive layer was calculated for each animal (n). Following the ROI selection, the mean value was obtained from the fluorescence intensity values from these five regions. We obtained the median value by plotting the median values from all arteries within an experimental group. This value was posteriorly summed with the other animals' values from the same group of treatment in order to reach the mean \pm SEM. The ethidium (DHE) fluorescence is emitted by the cellular nuclei, in this sense each designed ROI was guided by this organelle.

\subsection{Solutions and Drugs}

Krebs PSS was prepared in deionised water at the day of the respective experiments. Salts were purchased from Synth (Diadema/SP-Brazil. Phenylephrine, (PHE) acetylcholine (ACh), HEPES (4-(2-hydroxyethyl)-1-piperazineethanesulfonic acid), dihydroethidium (DHE), DMSO and Resveratrol were obtained from Sigma-Aldrich (St. Louis, MO, USA). Stock solution of PHE and ACh were prepared in deionized water $(100 \mathrm{mmol} / \mathrm{L})$ and kept on $-20^{\circ} \mathrm{C}$. Stock solution DHE was prepared in DMSO $(0.01 \mathrm{~mol} / \mathrm{L})$, and kept on $-20^{\circ} \mathrm{C}$. Resveratrol was dissolved in deionised water with $0.05 \%$ Tween 80 at the day of the treatment.

\subsection{Data Analysis}

Results were expressed as the mean \pm SEM, and $\mathrm{n}$ indicates the number of animals. Statistical significance was evaluated by analysis of variance (one-way ANOVA) and post hoc test Newman Keuls by GraphPad Prism ${ }^{\circledR}$ 5.0 Software (San Diego, CA-USA). Values of $p<0.05$ were considered to be significant. The pharmacological parameters analyzed from concentration-effect curves to phenylephrine were represented by the $p \mathrm{D}_{2}(-\log E C 50$ : negative logarithm of the molar concentration of the drug required to promotes $50 \%$ of the maximal effect) and the Emax (maximal contraction) values. The EC50 values were calculated by means of linear regression analysis from complete concentration-effect curves in individual experiments.

\section{Results}

\subsection{Systolic Blood Pressure}

The values of the SBP are shown in the Figure 1 and represent data from the measurement at the end of the 
sixth week.

The treatment with resveratrol has significantly reduced the hypertensive level from the $2 \mathrm{~K}-1 \mathrm{C}$ Resv group $(79.1 \pm 4.9 \mathrm{mmHg}, n=23, p<0.01)$ when compared to the $2 \mathrm{~K}-1 \mathrm{C}$ control group $(196.6 \pm 6.0 \mathrm{mmHg}, n=15)$. This reduction did not reach the values from $2 \mathrm{~K}$ Resv group $(121.8 \pm 5.5 \mathrm{mmHg}, n=11)$ or the values from $2 \mathrm{~K}$ control group $(121.0 \pm 3.5 \mathrm{mmHg}, n=10)$.

\subsection{Cardiac Hypertrophy Index (CHI)}

The CHI in $2 \mathrm{~K}-1 \mathrm{C}$ control group ( $3.98 \pm 0.199, n=9$, $p<0.001$ ) was significantly higher compared to $2 \mathrm{~K}$ control group $(2.78 \pm 0.142, n=7, p<0.001)$. The treatment with resverat-rol did not alter the cardiac hypertrophy index in $2 \mathrm{~K}$ rats (2K Resv group: $2.75 \pm 0.13$, $n=7, p>0.001)$, but reduced it in $2 \mathrm{~K}-1 \mathrm{C}$ rats $(2 \mathrm{~K}-1 \mathrm{C}$ Resv group: $3.10 \pm 0.091, n=11, p<0.001)$ to the $2 \mathrm{~K}$ control group levels (Figure 2). CHI in 2K-1C Resv group was statistically similar to the value obtained in $2 \mathrm{~K}$ control or $2 \mathrm{~K}$ Resv groups.

\subsection{Vascular Reactivity}

The concentration-effect curves evoked by phenylephrine (PHE: $0.01 \mathrm{nmol} / \mathrm{L}-10 \mu \mathrm{mol} / \mathrm{L}$ ) in endothelium denude aortic rings were constructed. Contractions stimulated in preparations from $2 \mathrm{~K}-1 \mathrm{C}$ control group (Emax: $100 \pm$ $0.033 \% ; \mathrm{pD} 2=7.6 \pm 0.27, n=5$ ) were not statistically preparations from $2 \mathrm{~K}-1 \mathrm{C}$ control group (Emax: $100 \pm$

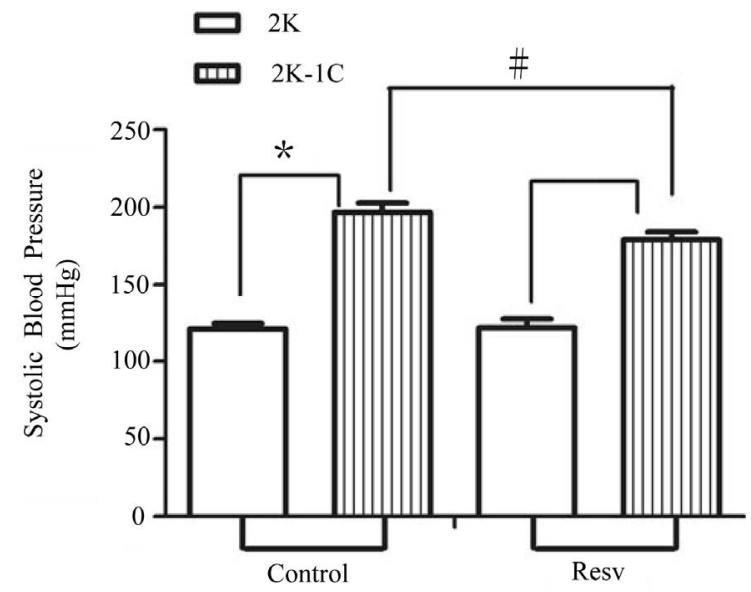

Figure 1. Effect of the treatment with resveratrol on the Systolic Blood Pressure (SBP) of the hypertensive rats. SBP was measured by tail cuff method before and after six weeks of treatment with resveratrol (Resv $20 \mathrm{mg} / \mathrm{Kg}$ ) or control (treatment with water + Tween 80 ). Values represents the measurement at the end of treatments and are expressed as mean $\pm \operatorname{SEM}(n=10-23)$. "Difference between the $2 \mathrm{~K}-1 \mathrm{C}$ control vs. $2 \mathrm{~K}$ control and $2 \mathrm{~K}-1 \mathrm{C}$ Resv vs. $2 \mathrm{~K}$ resv $(p<0.01)$. ${ }^{\text {Difference between } 2 \mathrm{~K}-1 \mathrm{C} \text { Resv (treated }}$ with resveratrol) and $2 \mathrm{~K}-1 \mathrm{C}$ control (non-treated). ANOVA, one way; Neuman-Keuls' post-test. different from that one evoked in $2 \mathrm{~K}$ control rat aorta (Emax: $98.79 \pm 0.74 \% ; p D 2=7.07 \pm 0.15, n=5$ ). At the same way, the contraction evoked by phenylephrine in aorta from $2 \mathrm{~K}$ Resv group (Emax: $99.25 \pm 2.71 \%$; pD2: $8.6 \pm 0.27, n=5$ ) or $2 \mathrm{~K}-1 \mathrm{C}$ Resv group (Emax: $97.32 \pm$ $2.39 \% ; p \mathrm{D} 2: 7.5 \pm 0.057, n=5$ ) was not different from that one evoked in aorta from $2 \mathrm{~K}$ control group (Figure 3).

\subsection{Vascular ROS Measurement}

Basal DHE fluorescence results are shown in the Figure

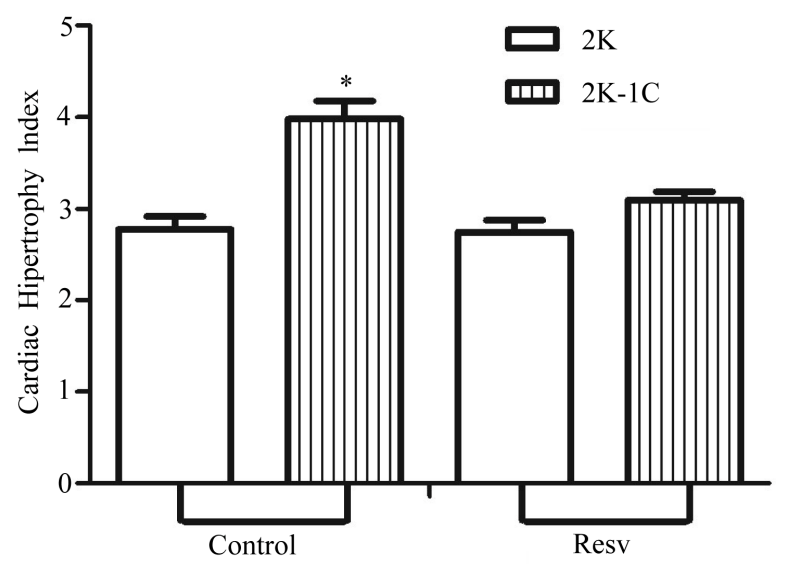

Figura 2. Effect of resveratrol treatment on cardiac hypertrophy index (heart wet weight $(\mathrm{mg}) /$ body weight $(\mathrm{g})$ ) of $2 \mathrm{~K}$ and $2 \mathrm{~K}-1 \mathrm{C}$ rats treated with resveratrol (resv $20 \mathrm{mg} / \mathrm{Kg}$ ) or control (treatment with water + Tween 80) during six weeks. Y-axis is represented in the cardiac hypertrophy index for different groups of animals. Values are expressed as mean $\pm \operatorname{SEM}(n=7-11)$. " Indicates statistical difference between the control $2 \mathrm{~K}-1 \mathrm{C}$ and the other groups. One way analysis of variance (ANOVA), Neuman-Keuls post test.

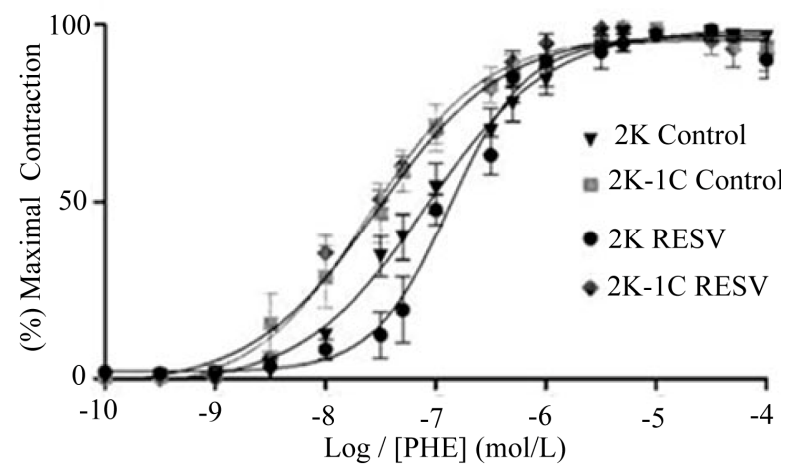

Figure 3. Effect of treatment with resveratrol on vascular reactivity to phenylephrine (PHE) in aortic rings isolated from $2 \mathrm{~K}$ and $2 \mathrm{~K}-1 \mathrm{C}$. The contractile-response curves were obtained by adding increasing cumulative concentrations of PHE (0.01 $\mathrm{nmol} / \mathrm{L}-10 \mu \mathrm{mol} / \mathrm{L})$ in isolated aortic rings without endothelium from $2 \mathrm{~K}$ and $2 \mathrm{~K}-1 \mathrm{C}$ treated with resveratrol (Resv $20 \mathrm{mg} / \mathrm{Kg}$ ) or control (water + Tween 80) for six weeks. Values are expressed as mean $\pm \operatorname{SEM}(n=5)$. 
4(a) and the DHE fluorescence results after stimulation with phenylephrine are shown in the Figure 4(b).

Comparing the respective arterial layers, the basal DHE fluorescence intensity emitted by the endothelial $(35.70 \pm 4.826, n=4, p<0.0001)$ or muscular $(79.09 \pm$ $8.468, n=4, p<0.001$ ) layers of the aorta from $2 \mathrm{~K}-1 \mathrm{C}$ control group was significantly higher than the basal DHE fluorescence intensity emitted by the endothelial $(5.133 \pm 1.535, n=4, p<0.0001)$ or the muscular $(12.43$ $\pm 1.896, n=4, p<0.001$ ) layers of the aorta from $2 \mathrm{~K}$ control group, respectively (Figure 4(a)). The treatment with resveratrol did not alter the basal DHE fluorescence both in the endothelial $(4.13 \pm 0.165, n=4)$ or the muscular $(15.307 \pm 2.397, n=4)$ layers of the aorta from $2 \mathrm{~K}$ Resv group when compared to the $2 \mathrm{~K}$ control group. On the other hand, the basal DHE fluorescence was signifycantly reduced after resveratrol treatment in the endothelial $(7.097 \pm 2.032, n=4)$ or muscular $(28.365 \pm 8.680, n$ $=4$ ) layers of the aorta from $2 \mathrm{~K}-1 \mathrm{C}$ Resv group, when compared to the $2 \mathrm{~K}-1 \mathrm{C}$ control group (Figure 4(a)).

The Figure 4(b) represents the DHE fluorescence after the stimulus with the alpha-1 agonist, phenylephrine. Phenylephrine did not alter the basal DHE fluorescence emitted by the endothelial $(6.123 \pm 1.406, n=4)$ or muscular $(14.953 \pm 3.256, n=4)$ layers of the aorta from $2 \mathrm{~K}$ control group when compared to the endothelial $(4.300 \pm 0.138, n=4)$ or muscular layers $(13.857 \pm 9.074$, $n=4$ ) of the aorta from $2 \mathrm{~K}$ Resv group, respectively.
Conversely, phenylephrine increased the basal DHE fluorescence emitted by the endothelial $(68.635 \pm 11.501, n=$ $4, p<0.0001)$ or muscular $(121.442 \pm 9.074, n=4, p<$ 0.0001 ) layers of the aorta from $2 \mathrm{~K}-1 \mathrm{C}$ control group the respective arterial layer of the aorta from $2 \mathrm{~K}$ control or Resv groups. Resveratrol treatment prevented the increase induced by phenylephrine in the basal DHE fluorescence emitted by the endothelial $(7.160 \pm 1.967, n=4$, $p<0.0001)$ or muscular $(28.327 \pm 8.585, n=4, p<$ 0.0001 ) layers of the aorta from $2 \mathrm{~K}-1 \mathrm{C}$ group (Figure 4(b)).

Figure 5 reports representative images from the ROS levels in aortic rings from $2 \mathrm{~K}$ or $2 \mathrm{~K}-1 \mathrm{C}$ control or Resv groups, detected by dihydroethidium (DHE) staining in confocal microscopy assays.

\section{Discussion}

The results clearly demonstrated the benefits of resveratrol treatment over cardiovascular indexes that are related renovascular hypertensive condition. It is possible that part of the cardioprotective actions of resveratrol is through an effect on blood pressure.

Our first results showed a remarkable reduction of the systolic blood pressure due to the resveratrol treatment, reduction was obtained soon after surgery, i.e. just before the development of renal hypertension, when (micro) vascular and/or cardiac changes are starting to occur.

Antihypertensive effects of resveratrol have already been observed in other models/contexts such as rats fed

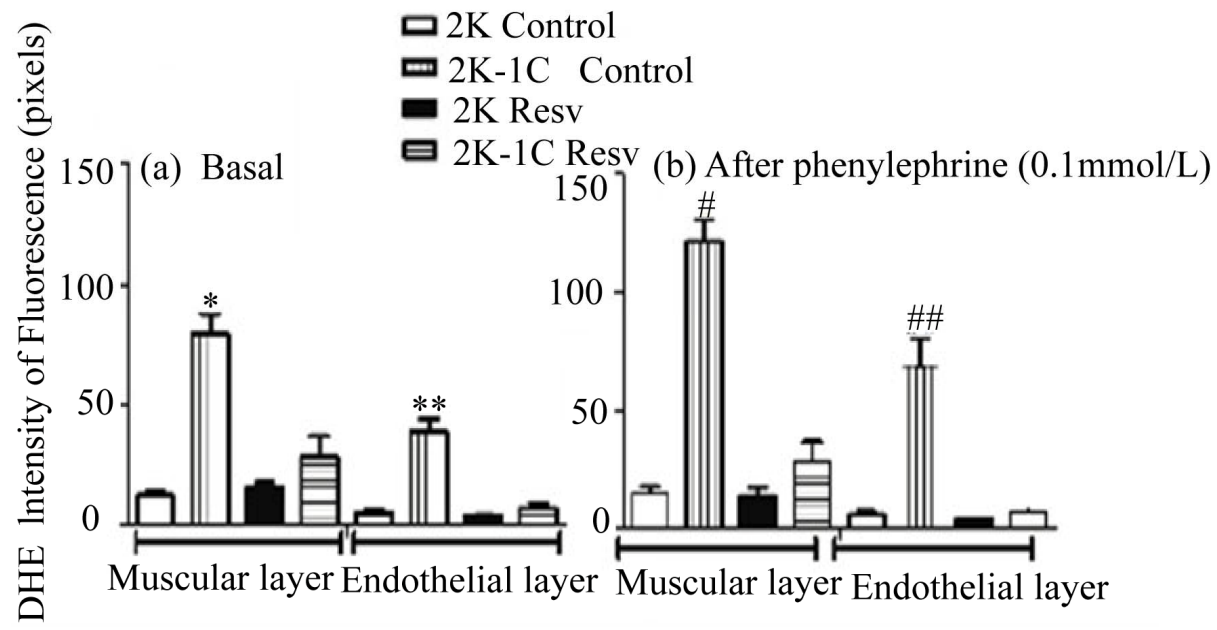

(a)

(b)

Figure 4. Effect of the treatment with resveratrol on the ROS (DHE staining), in both muscular and endothelial layers of the aortic rings isolated from $2 \mathrm{~K}$ and $2 \mathrm{~K}-1 \mathrm{C}$. Aortic rings isolated $2 \mathrm{~K}$ and $2 \mathrm{~K}-1 \mathrm{C}$ rats treated with resveratrol $(\mathrm{Resv} 20 \mathrm{mg} / \mathrm{Kg})$ or control (treatment with water + Tween 80) during six weeks were loaded with DHE $(50 \mu \mathrm{mol} / \mathrm{L})$. In the panel (a) is the basal fluorescence intensity (pixels): "indicates significant difference $(p<0.0001)$ between control $2 \mathrm{~K}-1 \mathrm{C}$ and the other groups in the muscular layer; ${ }^{* *}$ indicates significant difference $(p<0.0001)$ between control $2 \mathrm{~K}-1 \mathrm{C}$ and the other groups in the en-

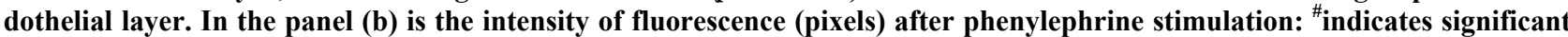
difference $(p<0.0001)$ between control $2 \mathrm{~K}-1 \mathrm{C}$ and the other groups in the muscular layer; ${ }^{\text {indicates significant difference }}$ $(p<0.0001)$ between group control $2 \mathrm{~K}-1 \mathrm{C}$ and the other groups in the endothelial layer. Values are expressed as mean \pm SEM $(n=4)$. One way analysis of variance (ANOVA), Neuman-Keuls post test. 


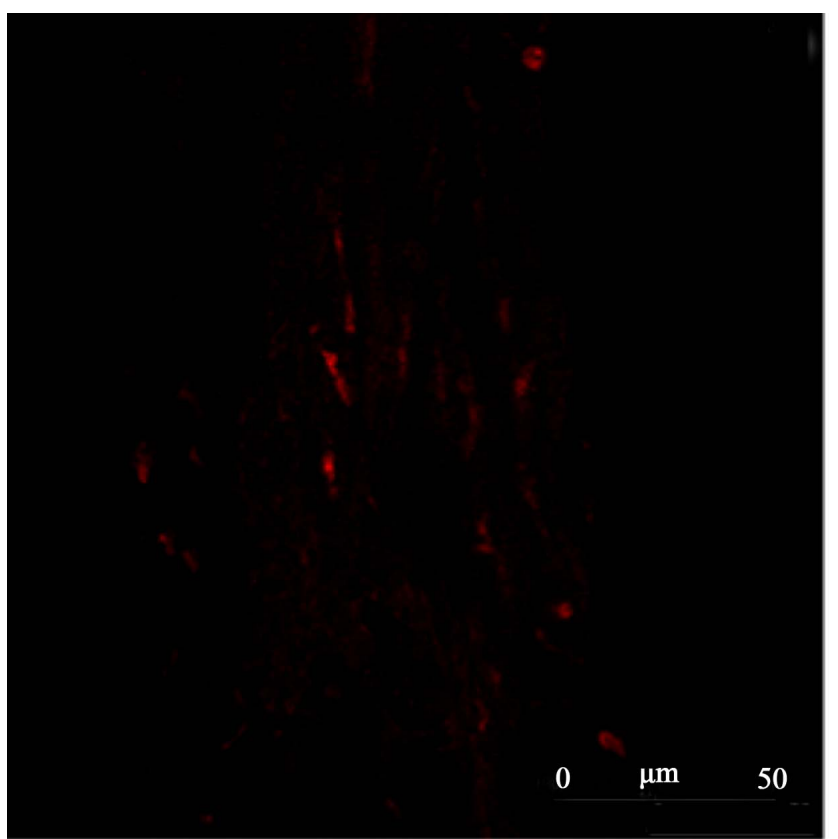

(a) $2 \mathrm{~K}$ Control

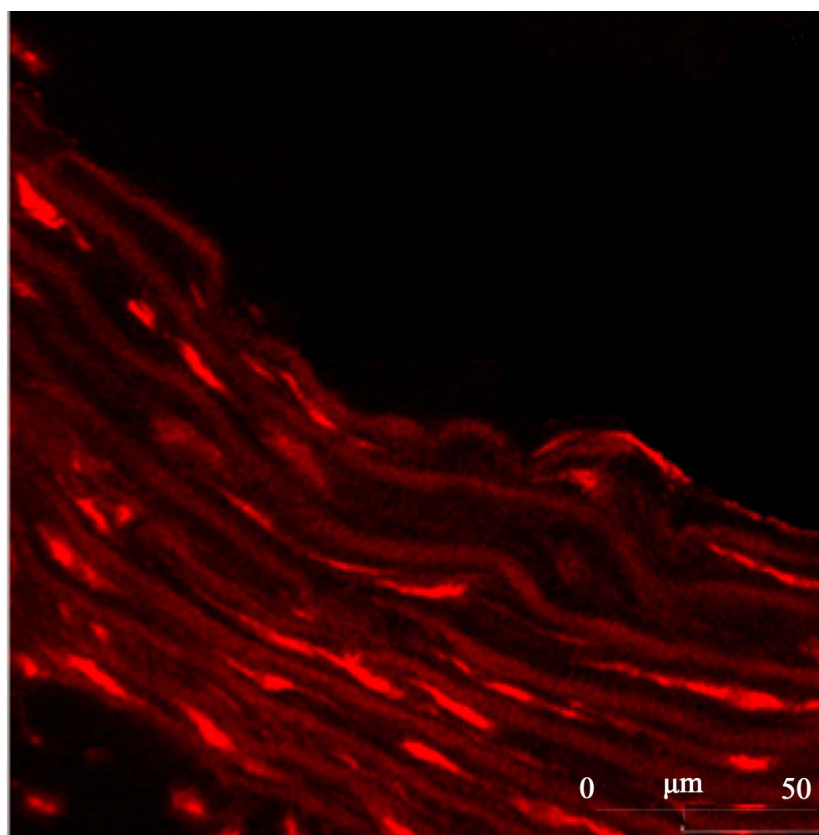

(b) $2 \mathrm{~K}-1 \mathrm{C}$ Control

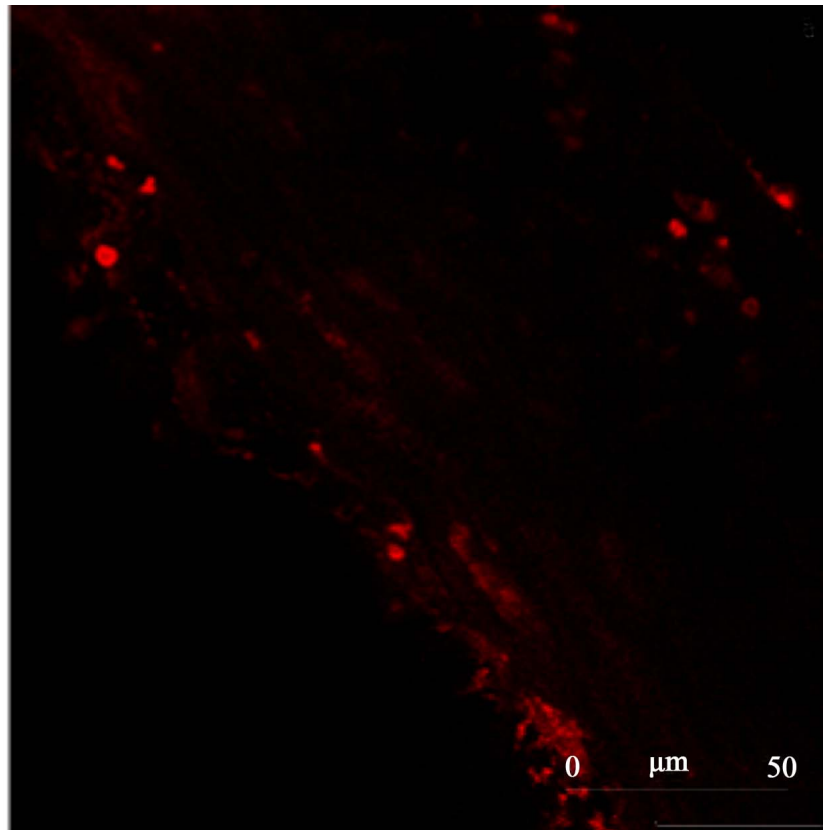

(d) 2 K-1C Resv

(c) $2 \mathrm{~K}$ Resv

Figure 5. Representative images from confocal microscopy of the ROS content in the aortic rings tissue detected by dihydroethidium (DHE) staining. Panel (a) 2K control (normotensive rats non-treated with resveratrol). Panel (b) 2K-1C control (hypertensive rats non-treated with resveratrol). Panel (c) $2 \mathrm{~K}$ treated with resveratrol (20 mg/Kg). Panel (d) 2K-1C treated with resveratrol $(20 \mathrm{mg} / \mathrm{Kg})$.

high-fat diets [35], partially nephrectomized rats [36] and the fructose-fed rat [37]. On the other hand, in spontaneously hypertensive rat (SHR), resveratrol administered from 10 to 20 weeks of age did not significantly reduce blood pressure [38].

An important consideration of the present study is that resveratrol was administered prior to the development of
2K-1C hypertension, but not after its establishment.

Our results are in agreement with the findings from Toklu et al. [39], who also studied the effect of resveratrol on the $2 \mathrm{~K}-1 \mathrm{C}$ hypertensive rats. Differently of our protocols, the authors had treated the animals via intraperitoneal and this treatment with resveratrol $(10 \mathrm{mg} / \mathrm{Kg})$ started after established the renal hypertension (i.e., in a curative approach). 
The Cardiac Hypertrophy Index in hypertensive 2K-1C rats was higher than the value observed in $2 \mathrm{~K}$ animals (Figure 2). This parameter is correlated with the renal hypertension, since it results from the hypertension and also contributes to the progression of this condition. The reduction of the cardiac hypertrophy index after resveratrol treatment is probably due to its antioxidant effects. There is an increased production of Ang II in this model of hypertension (renal hypertension), with consequent increase of ROS generations. Among these ROS, $\mathrm{H}_{2} \mathrm{O}_{2}$ can affect the contractile proteins leading to an impaired contraction of the cardiac myocytes, which consequently triggers cardiac hypertrophy as a compensatory mechanism. So that, resveratrol-treated hypertensive rats had fewer heart hypertrophy compared to non-treated hypertensive rats (Figure 2). This outcome is in accordance to Haider et al. [40], who showed that the hypertrophy induced by Ang II in vascular smooth muscle cells from normotensive rats was markedly reduced after resveratrol pre-treatment. The findings from Haider et al. [40] confirmed that part of protective effect of resveratrol is due to its action on the hypertrophy induced by Ang II.

It has been shown that resveratrol inhibits the ROSmediated increase in the activity of $\beta$-myosin heavy chain in cardiomyocytes and prevents the subsequent cardiac hypertrophy [41], which suggest that resveratrol may prevent vascular remodeling by reducing ROS bioavailability. Moreover, the production of ROS can be resultant from the genetic expression of the contractile $\beta$-myosin heavy chain ( $\beta$-MHC), previously altered by Ang II [18]. Also, ROS are responsible for potent effects in increasing extracellular matrix deposition and stimulating the proliferation of cardiac fibroblasts. Consequently, there are extracellular matrix metalloproteinases (endopeptidases) that degrade several extracellular matrix proteins by breaking them into their specific peptide bonds [42].

No change was observed on contractile responses induced by phenylephrine in endothelium-denude aortic rings from resveratrol-treated hypertensive rats (Figure 3). These results indicate that resveratrol was not effective in changing the aortic contractile response mediated by alpha 1adrenoceptors in the absence of endothelium, mainly in terms of the efficacy. The literature [43] indicates that phenylephrine-induced contraction is increased in endothelium-intact aorta from $2 \mathrm{~K}-1 \mathrm{C}$ hypertensive rats. Concerning vascular reactivity, our studies were conducted on aorta in the absence of endothelium in order to verify if the antioxidant treatment would avoid the known influence of catecholamines in inducingg vascular smooth muscle growth by influence of ROS [44]. In the vascularture, among the potential sources of ROS, we can find NADPH oxidase [45], which also regulates the myogenic constriction [46]. Besides that, ROS mediate the longterm effect of catecholamines in inducing alpha-adreno- ceptor-dependent hypertrophy of vascular smooth muscle cells and cardiomyocytes [44].

According to Tsai and Jiang [47], ROS are involved in the regulation of alpha1-adrenoceptor-mediated vascular smooth muscle contraction. However, in the present study, resveratrol treatment did influence neither the potency ( $p \mathrm{D}_{2}$ values) nor the efficacy (Emax) of contraction evoked by phenylephrine in endothelium-denuded aortic rings from $2 \mathrm{~K}-1 \mathrm{C}$ hypertensive rats. These data suggest that the specific ROS that could be involved on the modulation of the contraction induced by phenylephrine are not sensitive to this antioxidant polyphenol, and, therefore resveratrol did not alter these pharmacological parameters.

The chronic treatment of rats with resveratrol (gavage, $20 \mathrm{mg} / \mathrm{Kg}$, three times and a week, during six weeks) evoked local antioxidant effects in aorta. In fact, resveratrol reaches the arterial tissues during its distribution. The kinetic of the resveratrol has been widely studied and has been useful to be applied on the cardiovascular approaches. According to Baur and Sinclair [48], transresveratrol can accumulate in tissues resulting in a 30 -fold enrichment over serum concentrations. In addition, in vivo concentrations of bioactive metabolites can be more than 10 times higher than the native compound [48]. In this way, after treatment, it is assumed that the resveratrol keeps acting its biochemical properties on the target tissues. Several works, including preclinical and clinical evidences, have shown that oral treatment with resveratrol is effective in terms of keeping its antioxidant effect through mechanisms on the vascular actuation [49-53].

In our confocal microscopy results, it has been shown that the treatment with resveratrol allowed keeping locally its protective effect (i.e., its biological antioxidant property), acting as an antioxidant by reducing the local bioavailability of reactive oxygen species (ROS). Since the arterial samples, as soon after their isolation, were immediately loaded with dihydroethidium (DHE) and analyzed in the confocal microscope, the antioxidant effect of resveratrol can be promptly observed in the ex vivo arterial samples.

The intensity of dihydroethidium (DHE) staining as an indicator of ROS levels, particularly $\mathrm{O}^{-}$[54], indicated that the aortic ROS levels from $2 \mathrm{~K}-1 \mathrm{C}$ hypertensive rats were normalized after resveratrol treatment. In compareson to the resveratrol-treated groups, the basal DHE fluorescence intensity was significantly higher in both endothelial and muscular aortic layers from non-treated 2K-1C hypertensive rats (Figure 4(a)). The treatment with resveratrol caused a significant reduction in the aortic ROS levels from hypertensive rats. The both vascular layers reached the normotensive aortic ROS levels after treatment. This result confirms the antioxidant properties of resveratrol and its relevant role in avoiding damages 
triggered during hypertensive conditions. Although phenylephrine caused a significant increase in the fluorescence intensity in both endothelial and muscular layers of aortic rings from non-treated $2 \mathrm{~K}-1 \mathrm{C}$ rats, the contraction response induced by this alpha-1 adrenergic agonist did was not altered (as already discussed in Figure 3). Similarly to the basal DHE fluorescence intensity values, resveratrol significantly protected against the increase in the DHE fluorescence intensity induced by phenylephrine in aortic rings from $2 \mathrm{~K}-1 \mathrm{C}$ rats (Figure $4(\mathbf{b})$ ), pointing the antioxidant effect of resveratrol. The ROS in the aortic rings from $2 \mathrm{~K}-1 \mathrm{C}$ animals treated with resveratrol approximates the ROS present in the layers of the aorta of normotensive animals. This result showed the antioxidant effect of resveratrol in aortas from hypertensive rats, which is of paramount importance, because the endothelium-derived vasorelaxation, one of the mechanisms that controls blood pressure, is impaired by ROS-mediated pathways [55-57].

It has been described multiple protective effects associated with resveratrol besides its antioxidant activity [58]. Additionally to the inhibition of ROS, the antihypertensive effects of resveratrol, observed in our study, could be associated with the enhancement of the endothelial function, since resveratrol treatment seems to increase endothelial nitric oxide synthase (eNOS) expression and activity [59], improving NO production in male and female rats [60]. The increase in eNOS activity appears to be mediated by the estrogen receptor $\operatorname{ER} \alpha$, signaling through the $\alpha$-subunit of G-protein, caveolin-1, the tyrosine kinase $\mathrm{Src}$ and the mitogen activated protein kinase ERK1/2 [61]. Prevention of the development of concentric cardiac hypertrophy is reported for the treatment with lower doses of resveratrol, independent of blood pressure reduction $[62,63]$. Previous reports indicate that these effects may include the activation of the anti-hypertrophic AMPK-signaling pathway and inhibition of the prohypertrophic Akt signaling pathway and negative regulation of the calcineurin-nuclear factor of activated $\mathrm{T}$ cells (NFAT) pathway [64]. Unpublished data from our group has observed increase NFAT translocation in the left ventricle of $2 \mathrm{~K}-1 \mathrm{C}$ rats. Taken together, we can not exclude that other mechanisms could additionally contribute to the antihypertrophic properties of resveratrol beyond its antioxidant effects.

In brief, our findings allow us to conclude that the resveratrol treatment develops protective effects on the cardiovascular system in a preventive way. The antioxidant properties of resveratrol could also represent potential to enhance the current anti-hypertensive pharmacotherapeutic approaches.

\section{REFERENCES}

[1] M. Félétou and P. M. Vanhoutte, "Endothelial Dysfunction: A Multifaceted Disorder (The Wiggers Award Lec- ture)," The American Journal of Physiology (Heart and Circulatory Physiology), Vol. 291, No. 3, 2006, pp. H985-H1002.

[2] R. M. Touyz, "Intracellular Mechanisms Involved in Vascular Remodelling of Resistance Arteries in Hypertension: Role of Angiotensin II," Experimental Physiology, Vol. 90, No. 4, 2005, pp. 449-455.

[3] R. Humar, L. Zimmerli and E. Battegay, "Angiogenesis and Hypertension: An Update," Journal of Human Hypertension, Vol. 23, No. 12, 2009, pp. 773-782.

[4] M. Martinez-Maldonado, "Pathophysiology of Renovascular Hypertension," Hypertension, Vol. 17, No. 5, 1991, pp. 707719.

[5] H. Goldblatt, J. Lynch, R. F. Hanzal and W. W. Summerville, "Studies on Experimental Hypertension. The production of Persistent Elevation of Systolic Blood Pressure by Means of Renal Ischemia," The Journal of Experimental Medicine, Vol. 59, No. 3, 1934, pp. 347-349.

[6] C. M. Ferrario, "Importance of Rennin-AngiotensinAldosterone-System (RAS) in the Physiology and Pathology of Hyper-Tension," Drugs, Vol. 39, Suppl. 2, 1990, pp. 1-8.

[7] T. Heitzer, U. Wenzer, U. Hink, D. Krollner, M. Skatchkov, R. A. Stahl, R. MacHarzina, J. H. Bräsen, T. Meinertz and T. Münzel, "Increased NAD(P)H Oxidase Mediated Superoxide Production in Renovascular Hypertension Evidence for na Involvement of Protein Kinase C," Kidney International, Vol. 55, No. 1, 1999, pp. 252-260.

[8] L. O. Lerman, K. A. Nath, M. Rodriguez-Porcel, J. D. Krier, R. S. Schwartz, C. Napoli and J. C. Romero, "Increased Oxidative Stress in Experimental Renovascular Hypertension," Hypertension, Vol. 37, No. 2, 2001, pp. 541-546.

[9] Y. Higashi, S. Sasaki, K. Nakagawa, H. Matsuura, T. Oshima and K. Chayama, "Endothelial Function and Oxidative Stress in Renovascular Hypertension," The New England Journal of Medicine, Vol. 346, No. 25, 2002, pp. 1954-1962.

[10] C. Boulanger and T. F. Lüscher, "Release of Endothelin from the Porcine Aorta: Inhibition by Endothelium-Derived Nitric Oxide," Journal of Clinical Investigation, Vol. 85, No. 2, 1990, pp. 587-590.

[11] J. R. R. Fazan, V. J. D. Silva and H. C. Salgado, "Modelos de Hipertensão Arterial," Revista Brasileira de Hipertensão, Vol. 8, No. 1, 2001, pp. 19-29.

[12] G. De Simone, R. B. Devereux, M. Chinali, M. J. Roman, L. G. Best, T. K. Welty, E. T. Lee and B. V. Howard, "Strong Heart Study Investigators: Risk Factors for Arterial Hypertension in Adults with Initial Optimal Blood Pressure: The Strong Heart Study," Hypertension, Vol. 47, No. 2, 2006, pp. 162-167.

[13] M. Usui, K. Egashira, S. Kitamoto, M. Koyanagi, M. Katoh, C. Kataoka, H. Shimokawa and A. Takeshita, "Pathogenic Role of Oxidative Stress in Vascular Angiotensin-Converting Enzyme Activation in Long-Term Blockade of Nitric Oxide Synthesis in Rats," Hypertension, Vol. 34, No. 4, 1999, pp. 546-551. 
[14] S. Moncada and A. Higgs, "The L-Arginine-Nitric Oxide Pathway," The New England Journal of Medicine, Vol. 329, No. 27, 1993, pp. 2002-2012.

[15] R. Busse and I. Fleming, "Endothelial Dysfunction in Atherosclerosis," Journal of Vascular Research, Vol. 33, No. 3, 1996, pp. 181-194.

[16] D. G. Harrison, "Endothelial Function and Oxidant Stress," Clinical Cardiology, Vol. 20, No. 11, 1997, pp. II-11-II-17.

[17] G. Kojdaa and D. Harrisonb, "Interactions between NO and Reactive Oxygen Species: Pathophysiological Importance in Atherosclerosis, Hypertension, Diabetes and Heart Failure," Cardiovascular Research, Vol. 43, No. 3, 1999, pp. 562-571.

[18] G. P. Rossi, A. Sacchetto, M. Cesari and A. C. Pessina, "Interactions between Endothelin-1 and the Renin-Angiotensin-Aldosterone System," Cardiovascular Research, Vol. 43, No. 2, 1999, pp. 300-307.

[19] N. Kaul, N. Siveski-Iliskovic, M. Hill, J. Slezak and K. Singal, "Free Radicals and the Heart," Journal of Pharmacological and Toxicological Methods, Vol. 30, No. 2, 1993, pp. 55-67.

[20] P. K. Singal, N. Khaper, A. Belló-Klein and M. Bhayana, "Oxidative Stress Status in the Transition of Hypertrophy to Heart Failure," Heart Failure Reviews, Vol. 4, No. 4, 1999, pp. 353-360.

[21] P. K. Singal, N. Khaper, F. Farahmand and A. BellóKlein, "Oxidative Stress in Congestive Heart Failure," Current Cardiology Reports, Vol. 2, No. 3, 2000, pp. 206-211.

[22] K. Kathy, K. K. Griendling, A. Garret and M. D. FitzGerald, "Oxidative Stress and Cardiovascular Injury," Circulation, Vol. 108, 2003, pp. 1912-1916.

[23] F. Liao, A. Andalibi, J. H. Qiao, H. Allayee, A. M. Fogelman and A. J. Lusis, "Genetic Evidence for a Common Pathway Mediating Oxidative Stress, Inflammatory Gene Induction, and Aortic Fatty Streak Formation in Mice," The Journal of Clinical Investigation, Vol. 94, No. 2, 1994, pp. 877-884.

[24] B. Halliwell and J. M. Gutteridge, "Antioxidant Defences: Endogenous and Diet Derived," In: K. Davies, Ed., Free Radicals in Biology and Medicine, Elsevier Inc., New York, 2007.

[25] G. J. Soleas, E. P. Diamandis and G. D. M. Goldber, "Resveratrol: A Molecule Whose Time Has Come? And Gone?" Clinical Biochemistry, Vol. 30, No. 2, 1997, pp. 91-113.

[26] S. Renaud and M. D. Lorgeril, "Wine, Alcohol, Platelets, and the French Paradox for Coronary Heart Disease," Lancet, Vol. 339, No. 8808, 1992, pp. 1523-1526.

[27] L. Frémont, L. Belguendouz and S. Delpal, "Antioxidant Activity of Resveratrol and Alcohol-Free Wine Polyphenols Related to LDL Oxidation and Polyunsaturated Fatty Acids," Life Science, Vol. 64, No. 26, 1999, pp. 25112521.

[28] M. Murias, W. Jager, N. Handler, T. Erker, Z. Horvath, T. Szekeres, H. Nohl and L. Gille, "Antioxidant, Prooxi- dant and Cytotoxic Activity of Hydroxylated Resveratrol Analogues: Structure-Activity Relationship," Biochemical Pharmacology, Vol. 69, No. 6, 2005, pp. 903-912.

[29] T. Wallerath, D. Göran, T. Ternes, H. Anderson, H. Li, K. Witte and U. Förstermann, "Resveratrol, a Polyphenolic Phytoalexin Present in Red Wine, Enhances Expression and Activity of Endothelial Nitric Oxide Synthase," Circulation, Vol. 106, No. 13, 2002, pp. 1652-1658.

[30] M. E. Juan, M. P. Vinardell and J. M. Planas, "The Daily Oral Administration of High Doses of Trans-Resveratrol to Rats for 28 Days Is Not Harmful," Journal of Nutrition, Vol. 132, No. 2, 2002, pp. 257-260.

[31] R. E. Widdop and X. C. Li, “A Simple Versatile Method for Measuring Tail Cuff Systolic Blood Pressure in Conscious Rats," Clinical Science (London, England: 1979), Vol. 93, No. 3, 1997, pp. 191-194.

[32] A. S. Araújo, M. F. Ribeiro, A. Enzveiler, P. Schenkel, T. R. Fernandes, W. A. Partata, M. C. Irigoyen, S. Llesuy and A. Belló-Klein, "Myocardial Antioxidant Enzyme Activities and Concentration and Glutathione Metabolism in Experimental Hyperthyroidism," Molecular and Cellular Biochemistry, Vol. 240, No. 1-2, 2006, pp. 133-139.

[33] C. Urso and G. Caimi, "Oxidative Stress and Endothelial Dysfunction," Minerva Medica, Vol. 102, No. 1, 2011, pp. 59-77.

[34] R. Ross, "Atherosclerosis-An Inflamatory Disease," The New England Journal of Medicine, Vol. 340, No. 2, 1999, pp. 115-126.

[35] M. C. Aubin, C. Lajoie, R. Clément, H. Gosselin, A. Calderone and L. P. Perrault, "Female Rats Fed a High-Fat Diet Were Associated with Vascular Dysfunction and Cardiac Fibrosis in the Absence of Overt Obesity and Hyperlipidemia: Therapeutic Potential of Resveratrol," Journal of Pharmacology and Experimental Therapeutics, Vol. 325, No. 3, 2008, pp. 961-968.

[36] Z. Liu, Y. Song, X. Zhang, Z. Liu, W. Zhang, W. Mao, W. Wang, W. Cui, X. Zhang, X. Jia, N. Li, C. Han and C. Liu, "Effects of Trans-Resveratrol on HypertensionInduced Cardiac Hypertrophy Using the Partially Nephrectomized Rat Model," Clinical and Experimental Pharmacology and Physiology, Vol. 32, No. 12, 2005, pp. 1049-1054.

[37] R. Miatello, M. Vázquez, N. Renna, M. Cruzado, A. P. Zumino and N. Risler, "Chronic Administration of Resveratrol Prevents Biochemical Cardiovascular Changes in Fructose-Fed Rats," American Journal of Hypertension, Vol. 18, No. 6, 2005, pp. 864-870.

[38] J. Behbahani, S. J. Thandapilly, K. L. Louis, Y. Huang, Z. Shao, M. A. Kopilas, P. Wojciechowski, T. Netticadan and H. D. Anderson, "Resveratrol and Small Artery Compliance and Remodeling in the Spontaneously Hypertensive Rat," American Journal of Hypertension, Vol. 23, No. 12, 2010, pp. 1273-1278.

[39] H. Z. Toklu, O. Sehirli, M. Erşahin, S. Süleym0anoğlu, O. Yiğiner, E. Emekli-Alturfan, A. Yarat, B. Ç. Yeğen and G. Sener, "Resveratrol Improves Cardiovascular Function and Reduces Oxidative Organ Damage in the Renal, Cardiovascular and Cerebral Tissues of Two-Kidney, One- 
Clip Hypertensive Rats," Journal of Pharmacy and Pharmacology, Vol. 62, No. 12, 2010, pp. 1784-1793.

[40] U. G. B. Haider, D. Sorescu, K. K. Griendling, A. M. Vollmar and V. M. Dirsch, "Resveratrol Suppresses Angiotensin II-Induced Akt/Protein Kinase B and P70 S6 Kinase Phosphorylation and Subsequent Hypertrophy in Rat Aortic Smooth Muscle Cells," Molecular Pharmacology, Vol. 62, No. 4, 2002, pp. 772-777.

[41] T. H. Cheng, J. C. Liu, H. Lin, N. L. Shih, Y. L. Chen, M. T. Huang, P. Chan, C. F. Cheng and J. F. Chen, "Inhibitory Effect of Resveratrol on Angiotensin II-Induced Cardiomyocyte Hypertrophy," Naunyn-Schmiedeberg's Archives of Pharmacology, Vol. 369, No. 2, 2004, pp. 239244.

[42] E. Takimoto and D. A. Kass, "Role of Oxidative Stress in Cardiac Hypertrophy and Remodeling," Hypertension, Vol. 49, No. 2, 2007, pp. 241-248.

[43] G. E. Callera, A. Yogi, R. C. Tostes, L. V. Rossoni and L. M. Bendhack, "Ca2+ Activated $\mathrm{K}+$ Channels Underlying the Impaired Acetylcholine-Induced Vasodilation in $2 \mathrm{k}$ 1c Hypertensive Rats," The Journal of Pharmacology and Experimental Therapeutic, Vol. 309, No. 3, 2004, pp. 1036-1042.

[44] J. K. Amin, L. Xiao, D. R. Pimental, P. J. Pagano, K. Singh, D. B. Sawyer and W. S. Colucci, "Reactive Oxygen Species Mediate Alpha-Adrenergic Receptor-Stimulated Hypertrophy in Adult Rat Ventricular Myocytes," Journal of Molecular and Cellular Cardiology, Vol. 33, No. 1, 2011, pp. 131-139.

[45] H. Cai, K. K. Griendling and D. G. Harrison, "The Vascular NAD(P)H Oxidases as Therapeutic Targets in Cardiovascular Diseases," Trends in Pharmacological Sciences, Vol. 24, No. 9, 2003, pp. 471-478.

[46] P. T. Nowicki, S. Flavahan, H. Hassanain, S. Mitra, S. Holland, P. J. Goldschmidt-Clermont and N. A. Flavahan, "Redox Signaling of the Arteriolar Myogenic Response," Circulation Research, Vol. 89, No. 2, 2001, pp. 114-116.

[47] M. H. Tsai and M. J. Jiang, "Reactive Oxygen Species Are Involved in Regulating Alpha1-Adrenoceptor-Activated Vascular Smooth Muscle Contraction," Journal of Biomedical Science, Vol. 23, No. 17, 2010, p. 67.

[48] J. A. Baur and D. A. Sinclair, "Therapeutic Potential of Resveratrol: The in Vivo Evidence," Nature Reviews Drug Discovery, Vol. 5, No. 6, 2006, pp. 493-506.

[49] K. Mizutani, K. Ikeda, Y. Kawai and Y. Yamori, "Resveratrol Attenuates Ovariectomy-Induced Hypertension and Bone Loss in Stroke-Prone Spontaneously Hypertensive Rats," Journal of Nutritional Science and Vitaminology, Vol. 46, No. 2, 2000, pp. 78-83. doi: $10.3177 /$ insv. 46.78

[50] C. Silan, "The Effects of Chronic Resveratrol Treatment on Vascular Responsiveness of Streptozotocin-Induced Diabetic Rats," Biological \& Pharmaceutical Bulletin, Vol. 31, No. 5, 2008, pp. 897-902.

[51] H. Zhang, J. Zhang, Z. Ungvari and C. Zhang, "Resveratrol Improves Endothelial Function: Role of TNF A Alpha\} and Vascular Oxidative Stress," Arteriosclerosis, Thrombosis, and Vascular Biology, Vol. 29, No. 8, 2009, pp.
1164-1171.

[52] J. G. Zou, Z. R. Wang, Y. Z. Huang, K. J. Cao and L. M. Wu, "Effect of Red Wine And Wine Polyphenol Resveratrol on Endothelial Function in Hypercholesterolemic Rabbits," International Journal of Molecular Medicine, Vol. 11, No. 3, 2003, pp. 317-320.

[53] R. H. Wong, P. R. Howe, J. D. Buckley, A. M. Coates, I. Kunz and N. M. Berry, "Acute Resveratrol Supplementation Improves Flow-Mediated Dilatation in Overweight/ Obese Individuals with Mildly Elevated Blood Pressure," Nutrition, Metabolism \& Cardiovascular Diseases, Vol. 21, No. 11, 2011, pp. 851-856.

[54] P. Basu, N. Qipshidze, S. C. Tyagi and U. Sen, "Remodeling in Vein Expresses Arterial Phenotype in Hyperhomocysteinemia," International Journal of Physiology, Pathophysiology and Pharmacology, Vol. 3, No. 4, 2011, pp. 266-279.

[55] U. Landmesser, S. Dikalov, S. R. Pric, L. MCcann, T. Fukai, S. M. Holland, W. E. Mitch and D. G. Harrison, "Oxidation of Tetrahydrobiopterin Leads to Uncoupling of Endothelial Cell Nitric Oxide Synthase in Hypertension," The Journal of Clinical Investigation, Vol. 111, No. 8, 2003, pp. 1201-1209.

[56] R. M. Touyz, "Reactive Oxygen Species in Vascular Biology: Role in Arterial Hypertension," Expert Review of Cardiovascular Therapy, Vol. 1, No. 1, 2003, pp. 91106.

[57] B. Lasségue and K. K. Griendling, "Reactive Oxygen Species in Hypertension," American Journal of Hypertension, Vol. 17, No. 9, 2004, pp. 852-860.

[58] H. Li and N. Xia, "Förstermann. Cardiovascular Effects and Molecular Targets of Resveratrol," Nitric Oxide, Vol. 26, No. 2, 2012, pp. 102-110.

[59] U. Förstermann and H. Li, "Therapeutic Effect of Enhancing Endothelial Nitric Oxide Synthase (eNOS) Expression and Preventing eNOS Uncoupling," British Journal of Pharmacology, Vol. 164, No. 2, 2011, pp. 213-223.

[60] S. Soylemez, A. Sepici and F. Akar, "Resveratrol Supplementation Gender Independently Improves Endothelial Reactivity and Suppresses Superoxide Production in Healthy Rats," Cardiovascular Drugs and Therapy, Vol. 23, No, 6, 2009, pp. 449-458.

[61] C. M. Klinge, N. S. Wickramasinghe, M. M. Ivanova and S. M. Dougherty, "Resveratrol stimulates Nitric Oxide Production by Increasing Estrogen Receptor Alpha-SrcCaveolin-1 Interaction and Phosphorylation in Human Umbilical Vein Endothelial Cells," The FASEB Journal, Vol. 22, No. 7, 2008, pp. 2185-2197.

[62] V. W. Dolinsky, A. Y. Chan, I. R. Frayne, P. E. Light, C. Des Rosiers and J. R. Dyck, "Resveratrol Prevents the Prohypertrophic Effects of Oxidative Stress on LKB1," Circulation, Vol. 119, No. 12, 2009, pp. 1643-1652.

[63] S. J. Thandapilly, P. Wojciechowski, J. Behbahani, X. L. Louis, L. Yu, D. Juric, M. A. Kopilas, H. D. Anderson and T. Netticadan, "Resveratrol Prevents the Development of Pathological Cardiac Hypertrophy and Contrac- 
tile Dysfunction in the SHR without Lowering Blood Pressure," American Journal of Hypertension, Vol. 23, No. 2, 2010, pp. 192-196.

[64] A. Y. Chan, V. W. Dolinsky, C. L. Soltys, B. Viollet, S. Baksh, P. E. Light and J. R. Dyck, "Resveratrol Inhibits
Cardiac Hypertrophy via AMP-Activated Protein Kinase and Akt," The Journal of Biological Chemistry, Vol. 283, No. 35, 2008, pp. 24194-24201. 